\title{
SYR2, a gene necessary for syringomycin growth inhibition of Saccharomyces cerevisiae
}

\author{
Paul Cliften, ${ }^{1}$ Yeelan Wang, ${ }^{1}$ Daisuke Mochizuki, ${ }^{2}$ Tokichi Miyakawa, ${ }^{2}$ \\ Rungrach Wangspa,' Joanne Hughes' and Jon Y. Takemoto'
}

\author{
Author for correspondence: Jon Y. Takemoto. Tel: +1 801797 1909. Fax: +1 8017971575. \\ e-mail: Takemoto@cc.usu.edu
}

\author{
1 Department of Biology \\ and Program in Molecular \\ Biology, Utah State \\ University, Logan, UT \\ 84322-5305, USA \\ 2 Department of \\ Fermentation Technology, \\ Hiroshima University, 1-4-1 \\ Higashi-Hiroshima 739, \\ Japan
}

\begin{abstract}
The Pseudomonas syringae cyclic lipodepsipeptide syringomycin inhibits the growth of Saccharomyces cerevisiae. A novel yeast gene, SYR2, was found to complement two syringomycin-resistant S. cerevisiae mutants. SYR2 was cloned, sequenced, and shown to encode a 349 amino acid protein located in the endoplasmic reticulum. SYR2 was identical to SUR2, which is involved in survival during nutritional starvation. Gene disruption or overexpression of SYR2 did not affect cell viability or ergosterol levels, but did influence cellular phospholipid levels. The findings suggest that phospholipids are important for the growth inhibitory action of syringomycin.
\end{abstract}

Keywords: syringomycin, SYR2, Saccharomyces cerevisiae, SUR2, phospholipid biosynthesis

\section{INTRODUCTION}

Syringomycin is a small cyclic lipodepsipeptide produced by stone-fruit and grass isolates of Pseudomonas syringae $\mathrm{pv}$. syringae (Segre et al., 1989; Fukuchi et al., 1990; Takemoto, 1992). Generally considered a nonhost-specific phytotoxin (Gross \& DeVay, 1977), syringomycin also inhibits the growth of fungi, particularly yeasts such as Saccharomyces cerevisiae and Rhodotorula pilimanae (Zhang \& Takemoto, $1986,1987)$. Thus, it may play dual roles as a plant virulence factor and an antifungal agent against fungal competitors on plant surfaces (Takemoto, 1992). Several structurally related cyclic lipodepsipeptides produced by $P$. syringae strains have been identified. These include the syringostatins produced by a lilac isolate (Fukuchi et al., 1992), syringotoxin produced by citrus isolates (Ballio et al., 1990), and the pseudomycins produced from a barley isolate mutated with a transposon (Ballio et al., 1994).

The cellular site of action of syringomycin is the plasma membrane. It alters several membrane functions such as membrane potential, protein phosphorylation, $\mathrm{H}^{+}$ATPase activity and cation-transport fluxes (Zhang \& Takemoto, 1987, 1989; Bidwai et al., 1987; Bidwai \& Takemoto, 1987; Suzuki et al., 1992). The relationships of these activities and their relative importance in the response to syringomycin exposure are not clear. To learn more about the mode of action of syringomycin, recessive

Abbreviation: GST, glutathione S-transferase.

The GenBank accession number for the sequence reported in this paper is SCU10427. syringomycin-resistant strains of $S$. cerevisiae were isolated and characterized (Takemoto et al., 1991, 1993). One class of mutants (syr1) were deficient in membrane ergosterol and sensitive to high external $\mathrm{Ca}^{2+}$ levels. syr 1 mutants were complemented by gene $S Y R 1$ (identical to ERG3) that encodes the ergosterol biosynthetic enzyme C-5 sterol desaturase (Taguchi et al., 1994). Therefore, ergosterol is necessary for syringomycin action, and the binding of syringomycin to this lipid in the plasma membrane has been proposed (Julmanop et al., 1993). Other classes of syringomycin-resistant mutants with normal ergosterol levels have been identified (Takemoto et al., 1993). Such mutants presumably have defects in other genes whose products are necessary for syringomycin action.

In this paper, we describe the cloning and characterization of yeast gene SYR2 that complements certain syringomycin-resistant mutants with normal ergosterol levels. SYR2 is shown to be identical to SUR2 (Desfarges $e t$ al., 1993), which is involved in survival during nutritional starvation. The SYR2-encoded protein is shown to associate with the endoplasmic reticulum and to have a role in phospholipid metabolism. The findings suggest that phospholipids are important for syringomycin action.

\section{METHODS}

Organisms and general genetic methods. S. cerevisiae syringomycin-resistant mutants $13 \mathrm{~N}-\mathrm{F} 2$ and $3 \mathrm{~N}-\mathrm{H} 1$ were isolated from haploid strain $\mathrm{KZ1}-1 \mathrm{C}$ ( $M A T \mathrm{~T}$ bis 3 leu2 trp1 ura3), and were previously described by Takemoto et al. (1993). Syringomycin- 
resistant mutant $28 \mathrm{~N}-\mathrm{D} 6$ was also derived from $\mathrm{KZ1}-1 \mathrm{C}$ and was shown by diploid analysis to be in the same genetic complementation group as $13 \mathrm{~N}-\mathrm{F} 2$. Resistant mutant $3 \mathrm{~N}-\mathrm{H} 1$ was defective in $S Y R 1$ (also designated ERG3), which encodes the sterol biosynthetic enzyme C-5 sterol desaturase (Taguchi et al., 1994). For gene cloning, Escberichia coli strains DH5 and HB101 were used (Sambrook et al., 1989). Yeast plasmid shuttle vectors YCpN1 (Liu et al., 1991), YCp50 (Rose et al., 1987), YEp24 (Rose \& Broach, 1991) and pYES2 (Invitrogen) were used. Genomic libraries of KZ1-1C were prepared in YCp50 and YCpN1 as described by Rose \& Broach (1991). Yeast extract-peptone-dextrose (YPD), minimal salts-dextrose minus uracil (SD-URA) and minimal salts-galactose minus uracil (SGURA) growth media were prepared as described by Rose $e t$ al. (1990). Syringomycin was added to growth media at concentrations ranging from 0.5 to $2 \cdot 0 \mu \mathrm{g} \mathrm{ml}^{-1}$. Yeast transformations were done using the lithium acetate method (Ito et al., 1983) or by electroporation (Becker \& Guarente, 1991). After transformation, yeast cells from single colonies growing on selective agar media were suspended in $100 \mu \mathrm{l}$ water in microtitre plate wells. Cells were replica-plated onto YPD agar medium and YPD agar medium containing syringomycin. After $48 \mathrm{~h}$ the plates were visually inspected for clones showing little or no growth on syringomycin-containing plates but normal growth on plates without syringomycin. Genetic complementation tests of syringomycin-resistant strains were performed as previously described by Takemoto et al. (1993).

Syringomycin purification. Syringomycin ( $E$ form) was purified as described previously by Bidwai \& Takemoto (1987).

Nested deletion subcloning of SYR2. Nested deletions were performed using the Erase-a-Base system (Promega). A $4.8 \mathrm{~kb}$ $S Y R 2$ clone (SphI-SphI) contained in pBluescript II (Stratagene) was used. The plasmid was linearized at $K p n I$ and $S a l I$ restriction sites, and then subjected to exonuclease III digestion for varying lengths of time to unidirectionally excise portions of insert DNA. After exonuclease III excision, the DNA was treated in succession with $\mathrm{S} 1$ nuclease, Klenow DNA polymerase and T4 DNA ligase according to the manufacturer's protocol. The resulting SYR2 subclones were transferred to YCpN1 to test for functional complementation of syr 2 strains.

SYR2 nucleotide sequence determination. DNA sequencing was performed using the dideoxynucleotide chain-termination method (Sanger et al., 1977). Sequences were determined on both strands from clones prepared by nested deletion or from clones prepared with suitable restriction enzymes in pGEM-3Z (Promega).

Northern blot analysis. Yeast total RNA was isolated using TRI-Reagent (Molecular Research Center). RNA was treated with glyoxal and electrophoresed on $1 \%(\mathrm{w} / \mathrm{v})$ agarose gels as previously described (Franke et al., 1987). RNA fragments were transferred to nylon membranes as described by Sambrook $e$ t al. (1989). DNA probes were labelled with the ECL direct labelling and detection system (Amersham) and used for hybridization to the RNA fragments. A $1.2 \mathrm{~kb}$ Pst I-SphI $S Y R 2$ fragment created using PCR was used as the probe.

Cell fractionation and Western blot analysis. Two cell fractionation methods were employed. For small-scale preparations, the glass-bead lysis method of Harlow \& Lane (1988) was used. For large-scale preparations, a procedure similar to one described by Serrano (1983) was used. Yeast cells were grown to late exponential stage in $500 \mathrm{ml}$ YPD medium. Cells were centrifuged in a Beckman JA10 rotor at 5000 r.p.m. for $10 \mathrm{~min}$, and the cell pellets were washed with $1.5 \mathrm{M}$ sorbitol. The cells were resuspended in $40 \mathrm{ml}$ homogenizing buffer
(0.1 M Tris/HCl, pH 7·5, $5 \mathrm{mM}$ EDTA, $2 \mathrm{mM} \mathrm{DTT})$ and $6 \%$ (w/v) sorbitol. Zymolyase 100T (Seikagaku America; $200 \mathrm{U}$ ) was added. Cells were incubated at $30^{\circ} \mathrm{C}$ for $60-90 \mathrm{~min}$. Spheroplasts were collected, resuspended in $40 \mathrm{ml}$ ice-cold homogenizing buffer, and lysed using 15-20 strokes in a chilled Dounce glass homogenizer. Lysates from both preparations were centrifuged at $100000 \mathrm{~g}$ for $30 \mathrm{~min}$ at $4{ }^{\circ} \mathrm{C}$ to isolate the pelleted crude membranes. Crude membranes from the largescale isolation were fractionated using a sucrose step gradient containing $3 \mathrm{ml} 53 \%(\mathrm{w} / \mathrm{v})$ sucrose, $3.5 \mathrm{ml} 43 \%(\mathrm{w} / \mathrm{v})$ sucrose and $3.5 \mathrm{ml} 26 \%(\mathrm{w} / \mathrm{v})$ sucrose. The gradient was centrifuged overnight at $68000 \mathrm{~g}$ in a Beckman SW4 41 rotor at $4{ }^{\circ} \mathrm{C}$. Plasma and endoplasmic reticulum membrane fractions were collected from the lower and upper interfaces, respectively. Vanadatesensitive $\mathrm{H}^{+}$-ATPase and NADPH-cytochrome- $c$ oxidoreductase activities were used to verify the identification of the plasma and endoplasmic reticulum membrane fractions, respectively (Marriot \& Tanner, 1979). Samples (30-50 $\mu$ g protein per lane) were analysed by SDS-PAGE. After electrophoresis, the proteins were transferred to nitrocellulose membranes and Western-blotted as described by Harlow \& Lane (1988).

Protein determination. Protein concentrations were determined using Coomassie Protein Assay Reagent (Pierce) and BSA as standard.

Alkaline phosphatase treatment of crude membranes. Crude membranes ( $50 \mu \mathrm{g}$ protein) in $200 \mu \mathrm{l}$ phosphatase buffer $(10 \mathrm{mM}$ Tris/ $\mathrm{HCl}, \mathrm{pH} 9,1 \mathrm{mM} \mathrm{ZnCl}, 1 \mathrm{mM} \mathrm{MgCl}$ ) were treated with $17 \mathrm{U}$ alkaline phosphatase (Boehringer Mannheim) at $37^{\circ} \mathrm{C}$ for $30 \mathrm{~min}$

Preparation of Syr2 fusion protein and antiserum. The bacterial vector pGEX-KG (Guan \& Dixon, 1991) was used to prepare a Syr2-glutathione- $S$-transferase (GST) fusion protein. Initially, an EcoRI-SalI fragment containing intact SYR2 was cloned into the vector. Expression of this GST-Syr2 fusion protein severely restricted the growth of E. coli and the fusion protein was not isolated in sufficient quantities. Subsequently, the HpaI-SphI fragment from SYR2 (encoding the C-terminal 124 amino acids) (Fig. 2b) was inserted in-frame with the GST sequences to produce a GST-Syr2 fusion protein. The $5^{\prime}$-end of the fragment ( $H p a I)$ was ligated with blunt ends to the $S m a I$ site of the pGEX-KG vector. A HindIII site was borrowed from pBluescript II phagemid (Stratagene) and used to clone the $3^{\prime}$ end of SYR 2 into pGEX-KG at the corresponding site. E. coli HB101 was transformed with the construct. Upon IPTG induction, a $40 \mathrm{kDa}$ polypeptide presumed to be the fusion product was produced. The fusion protein was purified and the Syr2 peptide was cleaved with thrombin as described by Smith \& Johnson (1988). Peptide Syr2 was purified by SDS-PAGE using a $8-15 \%(\mathrm{w} / \mathrm{v})$ gradient polyacrylamide gel. After staining with Coomassie Blue, the Syr2 band was cut from the gel. The gel slice was fragmented and prepared for injection as described by Harlow \& Lane (1988). Rabbit antisera were prepared by immunizing rabbits with $75 \mu \mathrm{g}$ protein in Freund's complete adjuvant. Booster injections of $40 \mu \mathrm{g}$ protein in Freund's incomplete adjuvant were given $10-14 \mathrm{~d}$ before collection of sera. The sera were used directly for Western blot analysis.

To confirm the Syr2 peptide sequence, the peptide was transferred to Immobilon-P membrane (Millipore) using the method of LeGendre \& Matsudaira (1989). The membrane was stained with Coomassie Brilliant Blue, the Syr2 fragment was excised, and the $\mathrm{N}$-terminus ( 31 amino acids) was sequenced at the Utah State University Biotechnology Center (Logan, UT, USA). The sequence included two residues (Gly-Ser) encoded by vector sequences remaining after thrombin cleavage. 
SYR2 disruption. A $2.3 \mathrm{~kb}$ pBluescript clone of SYR2 created by nested deletion was used to construct the $S Y R 2$-disruptant strain. Plasmid C1 was constructed by replacing the HpaIEcoRV segment of SYR2 with a $1.2 \mathrm{~kb}$ HindIII fragment containing $U R A 3$ from plasmid YEp24. The $\mathrm{C} 1$ plasmid was digested with $S a c \mathrm{I}$ and $S p b \mathrm{I}$, and the resulting $3.14 \mathrm{~kb}$ linear fragment was purified and used to transform diploid strain W303-1A (MATa/MATa bis3 leu2 trp1 ura3). The one-step gene disruption method was used (Rothstein, 1983). Transformants were induced to sporulate, and the spores were dissected for tetrad analysis (Rose et al., 1990). A typical SYR2disrupted segregant was selected and designated strain W $\triangle S Y R 2$ and a corresponding nondisrupted strain was selected and designated W303C.

SYR2 overexpression. The PstI-SphI fragment of SYR2 was cloned into the $G A L 1$ promoter-containing vector pYES2 to yield pYSYR2. pYSYR2 allowed overexpression of SYR2 in SG-URA growth medium. The PstI-SpbI fragment was missing the first ATG start codon and the following 24 codons, yielding an expressed protein that was shorter than intact Syr2.

Chromosomal localization. Yeast chromosomes were separated by PFGE using a Bio-Rad CHEF DR-II system. Chromosomal DNA was electrophoresed in $1 \%(\mathrm{w} / \mathrm{v})$ agarose at $200 \mathrm{~V}$. Pulse time was $60 \mathrm{~s}$ for $15 \mathrm{~h}$ followed by $90 \mathrm{~s}$ for $9 \mathrm{~h}$. DNA for Southern blotting was digested with appropriate restriction enzymes and separated on $0.7 \%(\mathrm{w} / \mathrm{v})$ agarose gels. DNA was transferred to nylon membranes as described by Sambrook $e t a l$. (1989). The SYR2 probe was the same as described above for Northern blot analysis. A Dictyostelium actin- 8 probe was also used, prepared by digesting an actin-8 clone contained in pMB9 (Romans \& Firtel, 1985) (supplied by Dr Dennis L. Welker, Utah State University, UT, USA) with HindIII and labelling with the ECL system as described above.

Phospholipid and ergosterol analyses. Cells were extracted with chloroform/methanol $(3: 1, \mathrm{v} / \mathrm{v})$ and the phospholipids were purified as described by Radin (1969). Total lipid masses were determined after drying the chloroform/methanol lipid extracts. Total phospholipid phosphate amounts were determined using a modified Fiske \& Subbarow method described by Cooper (1977). Individual phospholipids were resolved by onedimensional TLC (silica gel G-60, Merck; $20 \times 20 \mathrm{~cm}$ ) using chloroform/methanol/acetic acid/water (25:15:4:2, by vol.) as the developing solvent. For phospholipid detection, plates were sprayed with molybdenum blue reagent (Dittmer \& Lester, 1964). Authentic samples of phosphatidylglycerol, phosphatidylethanolamine, phosphatidylinositol, phosphatidylserine and cardiolipin (Sigma) were used as standards. For ergosterol analysis, nonsaponifiable lipid extracts (Radin, 1969) were chromatographed on silica gel G-60 (Merck; $20 \times 20 \mathrm{~cm}$ ) thin-layer plates using $n$-hexane/diethyl ether/acetic acid $(70: 30: 1$, by vol.). After chromatography, the plates were sprayed with phosphomolybdic acid spray reagent (Sigma) for visualization of ergosterol.

\section{RESULTS}

\section{SYR2 cloning}

Genetic complementation analyses showed that syringomycin-tesistant strains $13 \mathrm{~N}-\mathrm{F} 2$ (Takemoto et al., 1993) and 28N-D6 had closely linked mutant alleles designated syr2. In contrast to other mutations that conferred syringomycin resistance, syr2 mutations did not affect ergosterol biosynthesis (Takemoto et al., 1993; Taguchi et al., 1994). Strains $13 \mathrm{~N}-\mathrm{F} 2$ and 28N-D6 were (a)

Clone $246(10.5 \mathrm{~kb})$

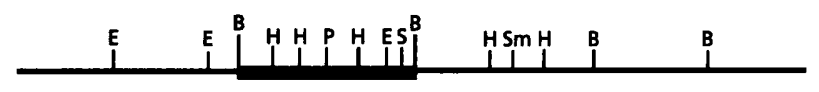

(b)

Subclone ( $2 \cdot 5 \mathrm{~kb})$

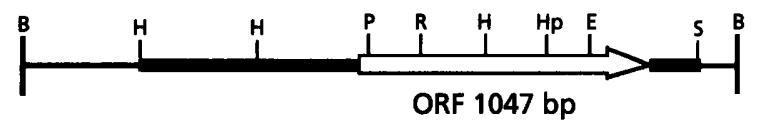

Fig. 1. Partial restriction maps of SYR2 clones. (a) Clone 246 $(10.5 \mathrm{~kb})$ isolated by complementation of the syr2 mutant $28 \mathrm{~N}$ D6. The SYR2 gene is located within a $2.5 \mathrm{~kb}$ BstBI fragment (bold line). (b) Restriction map of $2.5 \mathrm{~kb}$ BstBl clone 54 showing the sequenced region (bold) and the position of the SYR2 ORF. Restriction sites: H, HindIII; R, EcoRI; P, Pstl; E, EcoRV; B, BstBI; S, Sphl; Sm, Smal; Hp, Hpal.

transformed with genomic libraries prepared in yeast centromeric vectors YCpN1 and YCp50. Inserts for the two libraries averaged $12 \mathrm{~kb}$. Approximately 5000 transformants of each strain were screened for phenotypic complementation of syr2. Transformants were replicaplated onto YPD medium containing 1-2 $\mu$ g syringomycin $\mathrm{ml}^{-1}$ and inspected for growth after $48 \mathrm{~h}$. Plasmids were isolated from transformants that showed little or no growth with syringomycin. Five clones were isolated with inserts ranging from 10.5 to $14 \mathrm{~kb}$. Restriction fragment analysis revealed that the clones were allelic, containing large overlap regions (data not shown). The smallest clone, 246-D6 (derived from a YCpN1 library), was selected for isolation of the SYR2 gene (Fig. 1). The gene was subcloned on a $2.5 \mathrm{~kb}$ Bst $\mathrm{BI}$ fragment with restriction endonucleases and then on a $1.68 \mathrm{~kb}$ fragment by nested deletion. Smaller subclones generated by $\mathrm{S} 1$ nuclease treatment were not expressed in yeast, suggesting that coding or upstream regulatory sequences had been excised.

A portion of the $1.68 \mathrm{~kb}$ fragment was used as a probe for chromosomal mapping of SYR2. Yeast chromosomes of strain KZ1-1C were separated by CHEF gel electrophoresis and blotted onto nylon membranes. Hybridization of the SYR2 probe to chromosomal blots revealed that $S Y R 2$ is located on chromosome IV (Fig. 2). To look for genes having similar or overlapping function with SYR2, the strain KZ1-1C genome was hybridized to the SYR2 probe using low stringency conditions. No similar genes were found under hybridization conditions that allowed Dictyostelium actin-8 (Romans \& Firtel, 1985) to bind yeast actin genes (approximately $78 \%$ identity) (data not shown).

\section{Sequence analyses}

A $2 \mathrm{~kb}$ fragment that included the $1.68 \mathrm{~kb}$ fragment was sequenced. An ORF sequence was located, beginning at ATG position 270, containing 1047 nucleotides and 


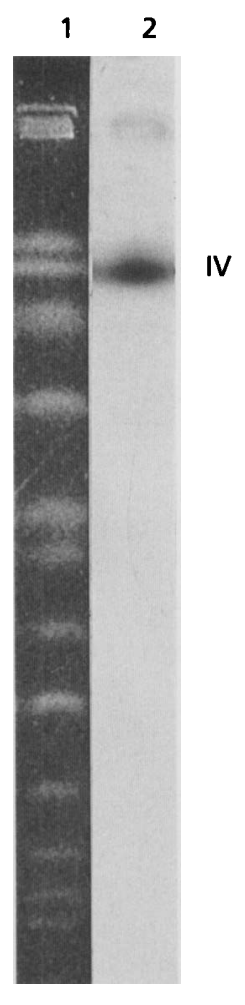

Fig. 2. Mapping of SYR2 to chromosome IV by hybridization to a CHEF gel blot. An ethidium-bromide-stained CHEF gel is shown in lane 1. Hybridization of the SYR2 probe to a blot of the CHEF gel is shown in lane 2.

predicted to encode a protein of 349 amino acids (Fig. 3). The ORF was preceded by regulatory sequences (CAAT) and (TATAA) beginning at positions -259 and -128 , respectively. Northern blot analysis showed a transcript of approximately $1.4 \mathrm{~kb}$ (data not shown), consistent in size with a polyA-modified transcript encoded by the ORF. The predicted amino acid sequence was confirmed by sequencing the $\mathrm{N}$-terminal 31 amino acids of a thrombin-cleaved GST-Syr2 (derived from a $\mathrm{HpaI}-\mathrm{S} p h \mathrm{I}$ DNA fragment of $S Y R 2$ ) fusion protein. The determined sequence (Thr227-Ala253) corresponded to the predicted sequence.

SYR2 (GenBank accession no. SCU10427) was identical to SUR2 (GenBank accession no. SCU07171), identified in $S$. cerevisiae and related to survival during nutrient starvation (Desfarges et al., 1993). No other homologues of the encoded Syr2/Sur2 protein were found in the standard protein computer databases.

Syr2 possessed the C-terminal dilysyl motif for retrieval to the endoplasmic reticulum (Letourneur et al., 1994). Syr2 hydropathy profiles suggested six potential membranespanning regions with hydrophobicity exceeding 1.25 using the parameters of Kyte \& Doolittle (1982) (Fig. 4). The C-terminus contained $26 \%$ lysine residues within a stretch of 50 residues, giving Syr2 an overall basic character. A pI of 9.32 was calculated. Potential protein phosphorylation and $\mathrm{N}$-glycosylation sites were revealed

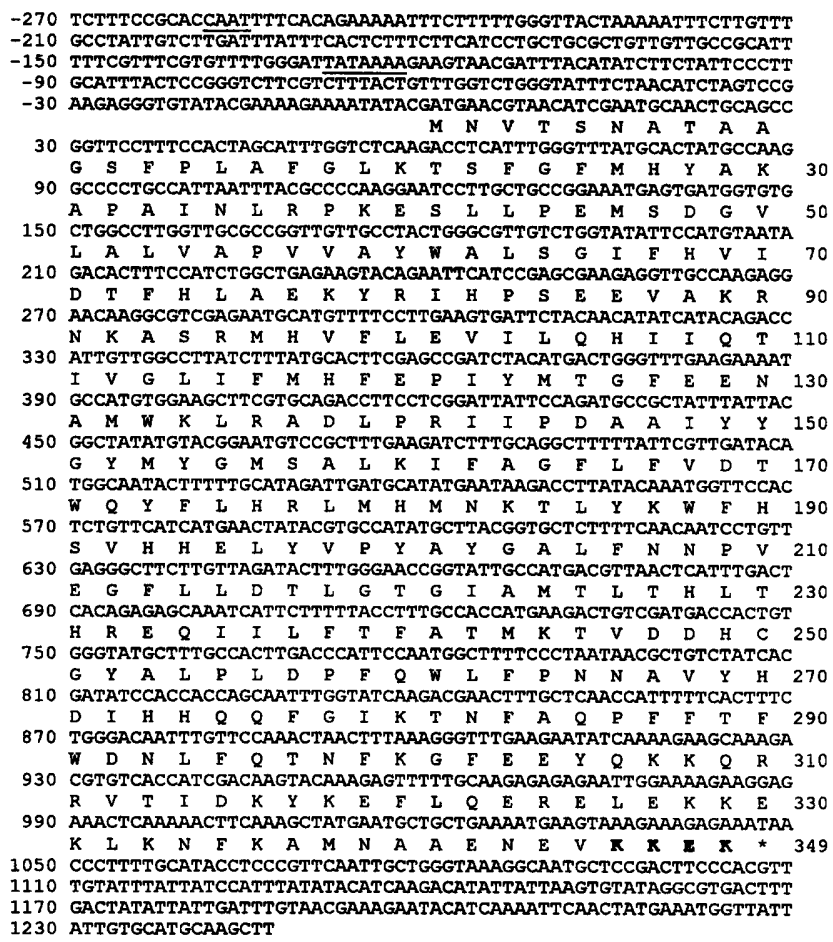

-270 TCTTTCCGCACCAATTTTCACAGAAAAATTTCTTTTTGGGTTACTAAAAATTTCTTGTTT -210 GCCTATTGTCTTGATTTATTTCACTCTTTCTTCATCCTGCTGCGCTGTTGTTGCCGCAT -150 TTTCGTTTCGTGTTTTGGGATTATAAAAGAAGTAACGATTTACATATCTTCTATTCCCTI -90 GCATTTACTCCGGGTCTTCGTCTTTACTGTTTGGTCTGGGTATTTCTAACATCTAGTCCG -30 AAGAGGGTGTATACGAAAGAAAATATACGATGAACGTAACATCGAATGCAACTGCAGCC 30 GGTTCCTTTCCACTAGCATTTGGTCTCAAGACCTCATTTGGGTTTATGCACTATGCCAAG G S F P L A F G L K T S F G F M H Y A K 90 GCCCCTGCCATTAATTIACGCCCCAAGGAATCCTSGCTGCCGGAAATGAGTGATGGTGTG $\begin{array}{lllllllllllllllllllll}A & P & A & I & N & I & R & P & K & E & S & L & L & P & E & M & S & D & G & V & 50\end{array}$ 150 CTGGCCTTGGTTGCGCGTTGTTGCTACTGGGCGTTGTCTGGTATATTCCATGTAATA $\begin{array}{llllllllllllllll}L & \text { I } & \text { V A } & \text { P V V } & \text { A } & Y & \text { W A } & \text { L } & \text { S } & G & I & F & H & V & I & 70\end{array}$ $\begin{array}{lllllllllllllllllllll}\text { D } & T & \mathbf{F} & \mathbf{H} & \mathbf{L} & \text { A } & \mathbf{E} & \mathbf{K} & \mathbf{Y} & \mathbf{R} & \mathbf{I} & \mathbf{H} & \mathbf{P} & \mathbf{S} & \mathbf{E} & \mathbf{E} & \mathbf{V} & \mathbf{A} & \mathbf{K} & \mathbf{R} & 90\end{array}$ 70 AACAAGGCG $\begin{array}{lllllllllllllllllllll}N & K & A & S & R & M & H & V & F & L & E & V & I & L & Q & H & I & I & Q & T & 110\end{array}$

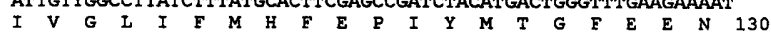
90 GCCATGTGGAAGCTTCGTGCAGACCTTCCTCGGATTATTCCAGATGCCGCTATTTATTAC

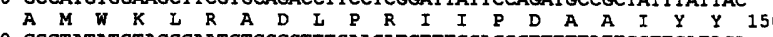
50 GGCTATATGTACGGATGTCCGCTTTGAAGATCTTTGCAGCCTT $\begin{array}{lllllllllllllllllllll}G & Y & M & Y & G & M & S & A & L & K & I & \mathbf{F} & A & \mathbf{G} & \mathbf{F} & \mathbf{L} & \mathbf{F} & \text { V } & \text { D } & \mathbf{T} & 170\end{array}$

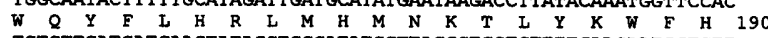
TCTGTTCATCATGAACTATACGTGCCATATGCTTACGGTGCTCTTTTCAACAATCCTGTT $\begin{array}{lllllllllllllllllllll}\mathbf{S} & \mathbf{V} & \mathbf{H} & \mathbf{H} & \mathbf{E} & \mathbf{L} & \mathbf{Y} & \mathbf{V} & \mathbf{P} & \mathbf{Y} & \mathbf{A} & \mathbf{Y} & \mathbf{G} & \mathbf{A} & \mathbf{L} & \mathbf{F} & \mathbf{N} & \mathbf{N} & \mathbf{P} & \mathbf{V} & 210\end{array}$

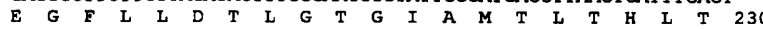
CACAGAGAGCAAATCATTCTTTTTACCTTTGCCACCATGAAGACTGTCGATGACCACTGT $\begin{array}{llllllllllllllllllllll}H & R & E & Q & I & I & L & F & T & F & A & T & M & K & T & V & D & D & H & C & 250\end{array}$ GGGTATGCTTTGCCACTTGACCCATTCCAATGGCTTTTCCCTAATAACGCTGTCTATCAC

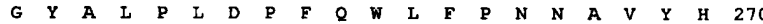
GATATCCACCACCAGCAATTTGGTATCAAGACGAACTTTGCTCAACCATTTTTCACTTTC $\begin{array}{llllllllllllllllllllll}D & I & H & H & Q & Q & F & G & I & K & T & N & F & A & Q & P & F & F & T & F & 290\end{array}$ TGGGACAATTTGTTCCAAACTAACTTTAAAGGGTTTGAAGAATATCAAAAGAAGCAAAGA $\begin{array}{llllllllllllllllllllll}W & D & N & L & F & Q & T & N & F & K & G & F & E & E & Y & Q & K & K & Q & R & 310\end{array}$ 930 CGTGTCACCATCGACAAGTACAAAGAGTTTTTGCAAGAGAGAGAATTGGAAAAGAAGGAG $\begin{array}{lllllllllllllllllllll}R & V & T & I & D & K & Y & K & E & F & L & Q & E & R & E & L & E & K & K & E & 330\end{array}$ 990 AAACTCAAAAACTTCAAAGCTATGAATGCTGCTGAAAATGAAGTAAAGAAAGAGAAATAA 1050 CCCTTTTGCATACCTCCCGTTCAATTGCTGGGTAAAGGCAATGCTCCGACTTCCCACGTT 1110 TGTATTTATTATCCATTTATATACATCAAGACATATTATTAAGTGTATAGGCGTGACTTT 1170 GACTATATTATTGATTTGTAACGAAAGAATACATCAAAATTCAACTATGAAATGGTTATT 1230 ATTGTGCATGCAAGCTT

Fig. 3. Nucleotide and predicted amino acid sequences of SYR2. Upstream transcriptional regulatory sequences (CAAT) and (TATAAAA) are underlined. The C-terminal endoplasmic reticulum retrieval signal is highlighted in bold. The asterisk indicates the position of translational termination.

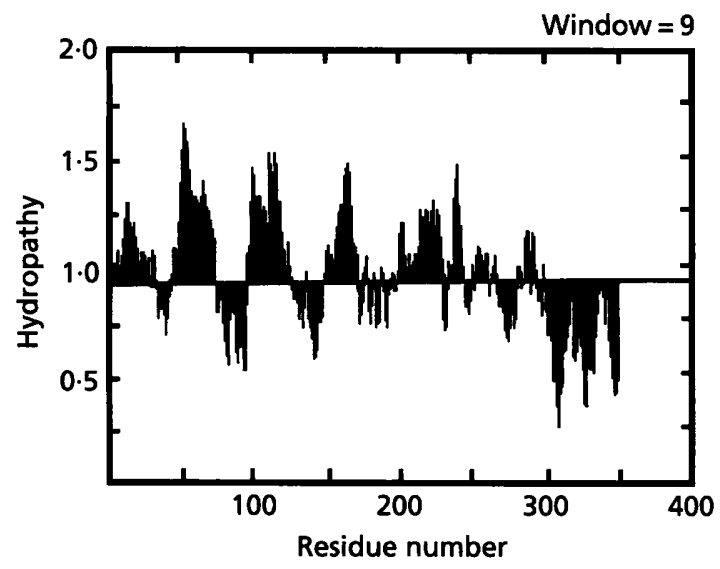

Fig. 4. Hydropathy plot of Syr2. Hydropathy was analysed as described by Kyte \& Doolittle (1982). Calculations were normalized on a scale from 0 to 2 .

using computer programs PROFILESCAN and MOTIF (GCG Corporation, Madison, WI, USA) (Altschul et al., 1990).

\section{SYR2 disruption}

All four meiotic segregants recovered after SYR2 disruption in diploid strain W303-1A were viable in YPD growth medium. A 2:2 cosegregation of syringomycin 
(a)

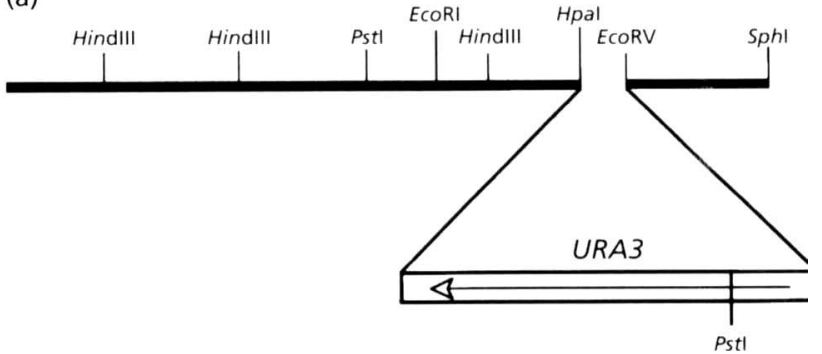

(b)

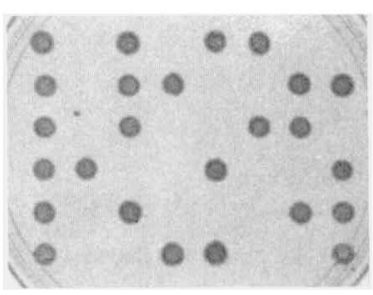

SD-URA

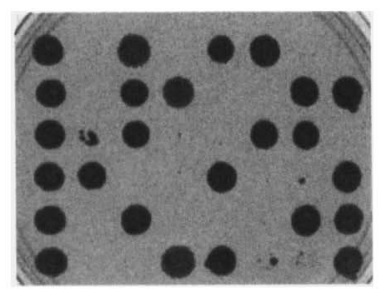

YPD + syringomycin

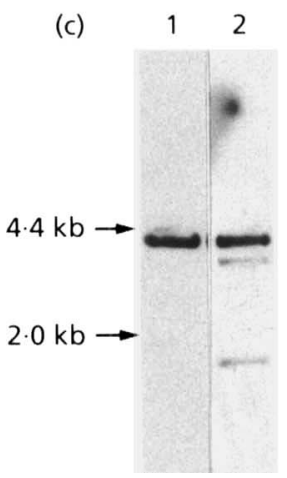

Fig. 5. Disruption of SYR2. (a) Structure of the DNA fragment used for the construction of the SYR2 null allele. (b) Tetrad analysis of the disrupted diploid showing cosegregation of syringomycin resistance and the URA3 marker. (c) Southern blot analysis of Pstl-digested genomic DNA from diploid strain W303-1A (lane 1) and SYR2-disruptant WASYR2 (lane 2). The URA3 marker contains a Pstl site $1.6 \mathrm{~kb}$ downstream of the SYR2 Pstl and creates two bands in the null allele.

resistance and $\mathrm{ura}^{+}$phenotypes occurred, indicating $U R A 3$ replacement in the wild-type SYR 2 allele (Fig. 5). Disruption was confirmed by Southern blot hybridization (Fig. 5c). No SYR2 transcripts were detected by Northern blot analyses in the disruptant strains. The W $\Delta S Y R 2$ segregants were viable in SD media and insensitive to ethanol, heat shock and high concentrations of sorbitol $(1 \cdot 25 \mathrm{M})$ and $\mathrm{Na}^{+}(1 \mathrm{M})$. They grew with maltose, galactose, glycerol and acetate as carbon sources.

\section{Syr2 detection and cell localization}

Western blot analysis using antisera directed against Syr2 identified an approximately $43 \mathrm{kDa}$ immunoreactive protein, which was slightly larger than the predicted mass of Syr2. The protein was detected in whole-cell extracts, microsomal fractions and endoplasmic reticulum mem-
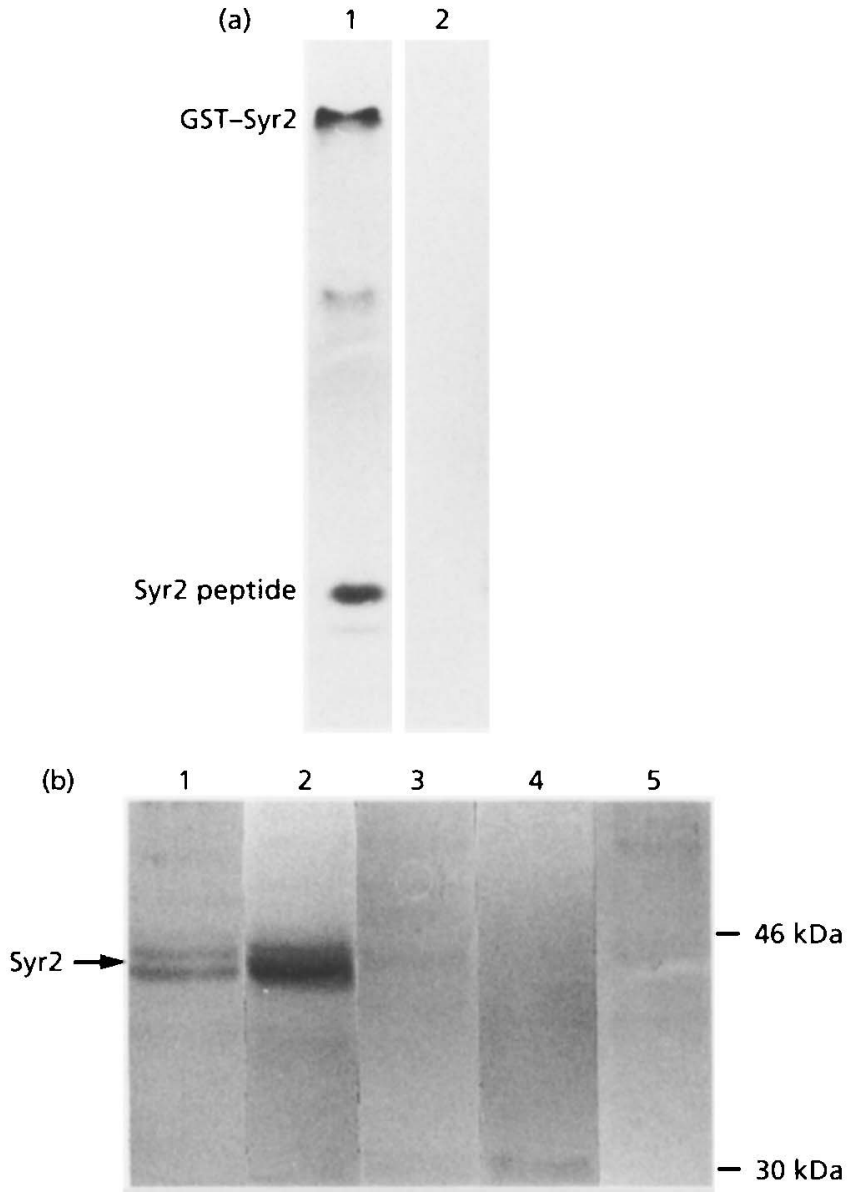

Fig. 6. Western blot analysis of Syr2. (a) Immunoreaction with the GST-Syr2 fusion protein and the Syr2 peptide that was used for antibody production (lane 1). Pre-immune sera did not react with either polypeptide (lane 2). (b) Immunoreaction to a $43 \mathrm{kDa}$ protein in yeast microsomal extracts (lane 1) and yeast extracts enriched for endoplasmic reticulum enzymes (lane 2). Syr2 was not detected in plasma membrane fractions (lane 3) or microsomal fractions prepared from SYR2-disrupted mutants (lane 4). Pre-immune sera did not react with microsomal extracts (lane 5).

branes, but not the plasma membrane (Fig. 6). The strongest immunoreaction occurred with the cellular fractions enriched for endoplasmic reticulum markers. Syr2 was not detected in extracts of the W $\Delta S Y R 2$ disruptants nor in extracts of strain $28 \mathrm{~N}-\mathrm{D} 6$. It was, however, detected in strain $13 \mathrm{~N}-\mathrm{F} 2$ membrane fractions.

In extracts from SYR2-overexpression strains, two equally intense immunoreactive bands on Western blots were often observed. This observation raised the possibility that Syr2 exists in two forms. To test the possibility that one form may be phosphorylated, crude membrane preparations were treated with alkaline phosphatase before SDS-PAGE and Western blotting. Both forms were still detected in the phosphatase-treated samples (data not shown). Likewise, no glycosylated form of Syr2 was evident after staining equivalent gels and blots with periodic acid/Schiff base reagent (data not shown). 


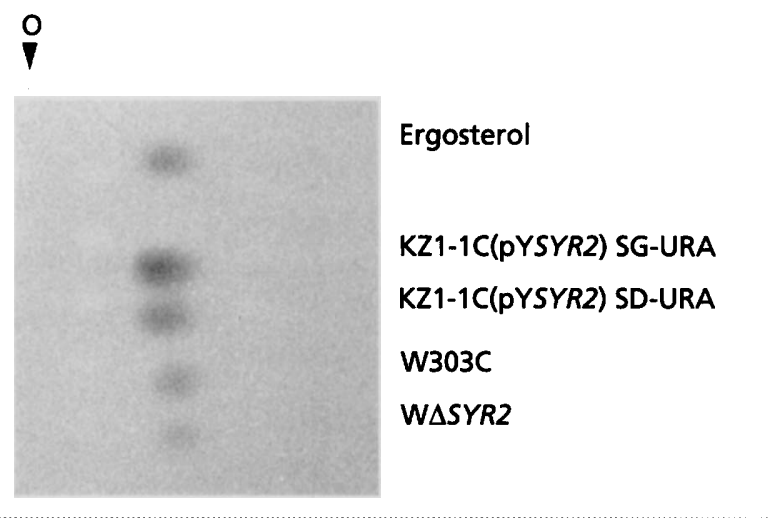

Fig. 7. Ergosterol levels in SYR2-overexpressing and disruption strains. Equal amounts (1 $\mathrm{mg}$ ) of total cell nonsaponifiable lipid extracts were chromatographed on thin-layer silica gel plates and stained with phosphomolybdic acid reagent. Authentic ergosterol (1 mg) was applied for comparison. The chromatographic origin (o) is indicated.

Table 1. Total cell phospholipid levels of SYR2overexpression and disruption strains

\begin{tabular}{|lcc|}
\hline Strain & Growth medium & $\begin{array}{c}\text { Lipid phosphate } \\
\text { [ug (mg dry wt } \\
\text { cells) }\end{array}$ \\
\hline KZ1-1C(pYSYR2)
\end{tabular}

* Values are means from three separate experiments. Standard deviations ( $n$-weighted) are indicated in parentheses.

\section{SYR2 overexpression}

To further analyse $S Y R 2$ function, overexpression vector pYSYR2, containing the PstI-SpbI portion of SYR2 under the regulation of the GAL1 promoter, was constructed. When syr 2 mutant strains $13 \mathrm{~N}-\mathrm{F} 2$ and $28 \mathrm{~N}-\mathrm{D} 6$ were transformed with pYSYR2 and grown in SG-URA medium, sensitivity to syringomycin was restored. Transformants W303C(pYSYR2) and KZ11C(pYSYR2) displayed syringomycin sensitivities comparable to the corresponding nontransformed strains, W303C and KZ1-1C, when grown in galactose-containing media. Also, pYSYR2 transformants of syr1 mutant $3 \mathrm{~N}-\mathrm{H} 1$ maintained levels of resistance to syringomycin in SG-URA medium similar to those of nontransformants. SYR2 overexpression was confirmed by Northern blot and Western blot analyses.

\section{Sterol and phospholipid compositions}

The cellular ergosterol levels of disruptant strain $\mathrm{W} \Delta S Y R 2$ and strain W303C were similar (Fig. 7). Also, the ergosterol levels of KZ1-1C(pYSYR2) cells grown in minimal medium with either galactose or glucose were similar (Fig. 7). In contrast, W $\Delta S Y R 2$ had lower levels of total cellular phospholipid (Table 1) and of phosphatidyl-

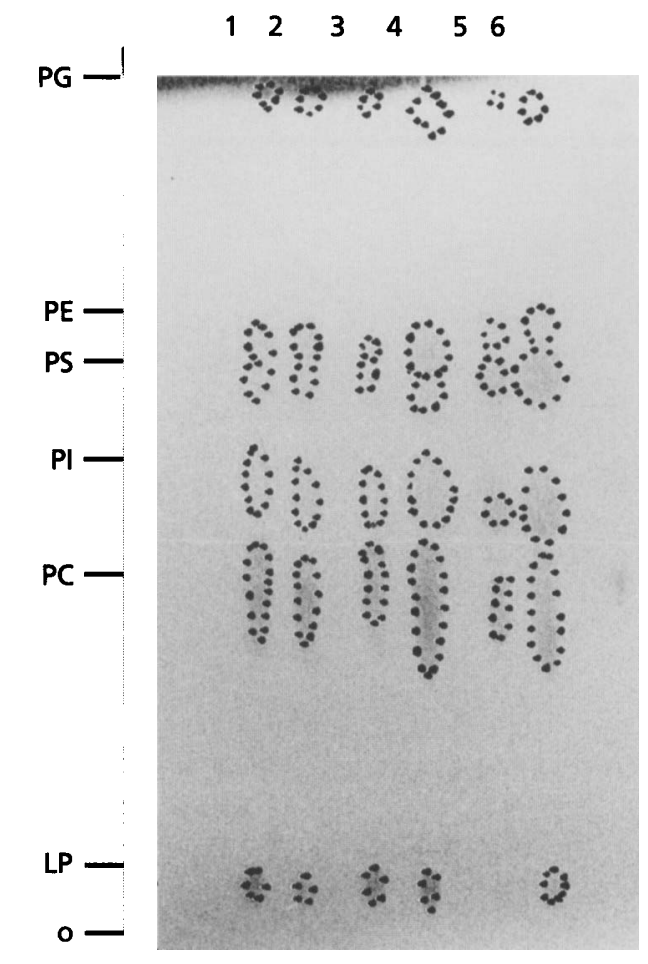

Fig. 8. Phospholipid profiles of SYR2-overexpressing and disruption strains. Equal amounts $(10 \mathrm{mg})$ of total cell lipid extracts of strains KZ1-1C(pYES2) grown in SD-URA medium (lane 1) and SG-URA medium (lane 2), KZ1-1C(pYSYR2) grown in SD-URA (lane 3) and SG-URA medium (lane 4), WDSYR2 (lane 5) and W303C (lane 6) were chromatographed on thin-layer silica gel G-60 plates and stained with molybdenum blue reagent. Positions of authentic lysophosphatidylcholine (LP), phosphatidylcholine (PC), phosphatidylinositol (PI), phosphatidylserine (PS), phosphatidylethanolamine (PE) and phosphatidylglycerol (PG) are indicated. The chromatographic origin (o) is indicated.

ethanolamine, phosphatidylserine and phosphatidylinositol (Fig. 8) than W303C. On the other hand, KZ1-1C(pYSYR2) cells grown with galactose had higher total cellular levels of phospholipids (Table 1) and of phosphatidylethanolamine, phosphatidylserine and phosphatidylinositol when compared to cells grown with glucose (Fig. 8).

\section{DISCUSSION}

It was determined in the present study that a novel gene, $S Y R 2$, is required for yeast growth inhibition by syringomycin. SYR2 differs from other identified syringomycin response genes since it does not involve ergosterol biosynthesis (Takemoto et al., 1993). Although its precise biochemical function is not known, $S Y R 2$ appears to have a role in cellular phospholipid biosynthesis. SYR2 is not essential for viability and, therefore, it is unlikely that it catalyses a critical step in the phospholipid biosynthetic pathways. Mutant syr2 alleles, however, lead to syringomycin resistance, indicating that normal phospholipid 
levels are required for syringomycin action. Previous work showed that the plasma membrane is the site of action of this lipodepsipeptide (Takemoto, 1992), and we suggest that the two major lipid classes of the yeast plasma membrane, ergosterol and phospholipids, are important for its action.

SYR2 is identical to the yeast gene SUR2. Mutant syr $2 /$ sur 2 alleles, as well as sur $1, \operatorname{sur} 3$ and sur 4 mutations, are suppressors of rvs161 (Desfarges et al., 1993), which impairs survival of yeast during nutrient starvation. Like syr $2 /$ sur 2 , sur 1 and sur 4 lead to alterations in the relative levels of various phospholipids. Desfarges et al. (1993) have hypothesized that all four identified SUR genes function in the same biochemical pathway.

Sequence analysis of Syr 2 revealed several potential sites for phosphorylation and $N$-glycosylation. However, evidence for covalent modification of Syr2 was not observed. Syr2 was often seen as a doublet on Western blots of crude extracts obtained from SYR2-overexpression strains. The doublet may reflect a modified or degraded form of Syr 2 . The overexpressed Syr2 did not possess an N-terminal signal sequence, eliminating the possibility that one form resulted from cleavage of a signal peptide.

Hydropathy profiles suggested that Syr2 is a membrane protein. As expected for an enzyme involved in phospholipid biosynthesis, an association with the endoplasmic reticulum was demonstrated. This location is consistent with the dilysyl motif at the C-terminus, which is an endoplasmic reticulum retrieval and coatamer interacting signal (Letourneur et al., 1994). Yeast proteins Wbp1p and C-5 sterol desaturase (encoded by ERG3/SYR 1 ) also contain this signal (Taguchi et al., 1994; Arthington et al., 1991; Te Heesen et al., 1992; Letourneur et al., 1994), and in the former, the dilysyl motif occurs in the cytoplasmic domain (Townsley \& Pelham, 1994; Gaynor et al., 1994). By analogy, we suggest that the Syr2 hydrophilic Cterminus is exposed on the cytoplasmic side of the endoplasmic reticulum.

\section{ACKNOWLEDGEMENTS}

This work was supported by the National Science Foundation (grant DCB 9003398). We thank S. Stock for technical assistance.

\section{REFERENCES}

Altschul, S. F., Gish, W., Miller, W., Meyers, E. W. \& Lipman, D. J. (1990). Basic local alignment search tool. J Mol Biol 215, 403-410.

Arthington, B. A., Bennett, L. G., Skatrud, P. L., Guynn, C. J., Barbuch, R. J., Ulbright, C. E. \& Bard, M. (1991). Cloning, disruption, and sequence of the gene encoding yeast C-5 sterol desaturase. Gene 102, 39-44.

Ballio, A., Bossa, F., Collina, A., Gallo, M., lacobellis, N. S., Paci, M., Pucci, P., Scaloni, A., Segre, A. \& Simmaco, M. (1990). Structure of syringotoxin, a bioactive metabolite of Pseudomonas syringae pv. syringae. FEBS Lett 269, 377-380.

Ballio, A., Bossa, F., Di Giorgio, D., Ferranti, P., Paci, M., Scaloni, A., Segre, A. \& Strobel, G. (1994). Novel bioactive lipo- depsipeptides from Pseudomonas syringae: the pseudomycins. FEBS Lett 355, 96-100.

Becker, D. M. \& Guarente, L. (1991). Transformation of yeast by electroporation. Methods Enzymol 194, 182-187.

Bidwai, A. P. \& Takemoto, J. Y. (1987). Bacterial phytotoxin, syringomycin, induces a protein kinase-mediated phosphorylation of red beet plasma membrane polypeptides. Proc Natl Acad Sci US $A$ 84, 6755-6759.

Bidwai, A. P., Bachmann, R. C. \& Takemoto, J. Y. (1987). Mechanism of action of Pseudomonas syringae phytotoxin syringomycin. Plant Pbysiol 83, 39-43.

Cooper, T. G. (1977). The Tools of Biochemistry. New York: John Wiley.

Desfarges, L., Durrens, P., Jugelin, H., Cassagne, C., Bonneu, M. \& Aigle, M. (1993). Yeast mutants affected in viability upon starvation have a modified phospholipid composition. Yeast 9, 267-277.

Dittmer, J. C. \& Lester, R. L. (1964). A simple, specific spray for the detection of phospholipids on thin-layer chromatograms. J Lipid Res 5, 126-127.

Franke, J., Podgorski, G. J. \& Kessin, R. H. (1987). The expression of two transcripts of the phosphodiesterase gene during development of Dictyostelium discoideum. Dev Biol 124, 504-511.

Fukuchi, N., Isogai, A., Yamashita, S., Suyama, K., Takemoto, J. Y. \& Suzuki, A. (1990). Structure of phytotoxin syringomycin produced by a sugar cane isolate of Pseudomonas syringae $\mathrm{pv}$ syringae. Tetrabedron Lett 31, 1589-1592.

Fukuchi, N., Isogai, A., Nakayama, J., Takayama, S., Yamashita, S., Suyama, K., Takemoto, J. Y. \& Suzuki, A. (1992). Structure and stereochemistry of three phytotoxins, syringomycin, syringotoxin and syringostatin, produced by Pseudomonas syringae pv. syringae. $J$ Chem Soc Perkin Trans 1, 1149-1157.

Gaynor, E. C., Te Heesen, S., Graham, T. R., Aebi, M. \& Emr, S. D. (1994). Signal-mediated retrieval of a membrane protein from the golgi to the ER in yeast. $J$ Cell Biol 127, 653-665.

Gross, D. C. \& DeVay, J. E. (1977). Role of syringomycin in holcus spot of maize and systemic necrosis of cowpea caused by Pseudomonas syringae. Physiol Plant Pathol 11, 1-11.

Guan, K. \& Dixon, J. E. (1991). Eukaryotic protein expressed in Escherichia coli: an improved thrombin cleavage and purification procedure of fusion protein with glutathione S-transferase. Anal Biochem 192, 262-267.

Harlow, E. \& Lane, D. (1988). Antibodies: a Laboratory Manual. Cold Spring Harbor, NY: Cold Spring Harbor Laboratory.

Ito, H., Fukuda, Y., Murata, K. \& Kimura, A. (1983). Transformation of intact yeast cells treated with alkali cations. $J$ Bacteriol 153, 163-168.

Julmanop, C., Takano, Y., Takemoto, J. Y. \& Miyakawa, T. (1993). Protection by sterols against the cytotoxicity of syringomycin in the yeast Saccharomyces cerevisiae. J Gen Microbiol 139, 2323-2327.

Kyte, J. \& Doolittle, R. F. (1982). A simple method for displaying the hydrophobic character of a protein. J Mol Biol 157, 105-132.

LeGendre, N. \& Matsudaira, P. (1989). Purification of proteins and peptides. In $A$ Practical Guide to Protein and Peptide Purification for Microsequencing, pp. 49-69. Edited by P. T. Matsudaira. San Diego: Academic Press.

Letourneur, F., Gaynor, F. C., Hennecke, S., Demolliere, C., Duden, R., Emr, S. D., Riezman, H. \& Cosson, P. (1994). Coatomer is essential for retrieval of dilysine-tagged proteins to the endoplasmic reticulum. Cell 79, 1199-1207.

Liu, Y., Ishii, S., Tokai, M., Tsutsumi, H., Ohki, O., Akada, R., Tanaka, K., Tsuchiya, E., Fukui, S. \& Miyakawa, T. (1991). The 
Sacharomyces cerevisiae genes (CMP1 and CMP2) encoding calmodulin-binding proteins homologous to the catalytic subunit of mammalian protein phosphatase 2B. Mol \& Gen Genet 227, 52-59.

Marriot, M. \& Tanner, W. (1979). Localization of dolichyl phosphate- and pyrophosphate-dependent glycosyl transfer reaction in Saccharomyces cerevisiae. J Bacteriol 139, 565-572.

Radin, N. S. (1969). Preparation of lipid extracts. Metbods Enzymol 14, 245-254.

Romans, P. \& Firtel, R. A. (1985). Organization of the actin multigene family of Dictyostelium discoideum and analysis of variability in the protein coding regions. $J$ Mol Biol 186, 321-335.

Rose, M. D. \& Broach, J. R. (1991). Cloning genes by complementation in yeast. Methods Enzymol 194, 195-230.

Rose, M. D., Novick, P., Thomas, J. H., Botstein, D. \& Fink, G. R. (1987). A Saccbaromyces cerevisiae genomic plasmid bank based on a centromere-containing shuttle vector. Gene 60, 237-243.

Rose, M. D., Winston, F. \& Heiter, P. (1990). Methods in Yeast Genetics: a Laboratory Manual. Cold Spring Harbor, NY: Cold Spring Harbor Laboratory.

Rothstein, R. J. (1983). One-step gene disruption in yeast. Methods Enzymol 101, 202-211.

Sambrook, J., Fritsch, E. F. \& Maniatis, T. (1989). Molecular Cloning: a Laboratory Manual, 2nd edn. Cold Spring Harbor, NY: Cold Spring Harbor Laboratory.

Sanger, F., Nicklen, S. \& Coulsen, A. R. (1977). DNA sequencing with chain-terminating inhibitors. Proc Natl Acad Sci USA 74, 5463-5467.

Segre, A., Bachmann, R. C., Ballio, A., Bossa, G., Grgurina, I., lacobellis, N. S., Pucci, P., Simmaco, M. \& Takemoto, J. Y. (1989). The structure of syringomycins $\mathrm{A} 1, \mathrm{E}$ and G. FEBS Lett 255, 27-31.

Serrano, R. (1983). In vivo glucose activation of the yeast plasma membrane ATPase. FEBS Lett 156, 11-14.

Smith, D. B. \& Johnson, K. S. (1988). Single-step purification of polypeptides expressed in Eschericbia coli as fusions with glutathione-S-transferase. Gene 67, 31-40.
Suzuki, Y. S., Wang, Y. \& Takemoto, J. Y. (1992). Syringomycinstimulated phosphorylation of the plasma membrane $\mathrm{H}^{+}$-ATPase from red beet storage tissue. Plant Physiol 99, 1314-1320.

Taguchi, N., Takano, Y., Julmanop, C., Wang, Y., Stock, S., Takemoto, J. \& Miyakawa, T. (1994). Identification and analysis of the Saccharomyces cerevisiae SYR1 gene reveals that ergosterol is involved in the action of syringomycin. Microbiology 140, 353-359.

Takemoto, J. Y. (1992). Bacterial phytotoxin syringomycin and its interaction with host membranes. In Molecular Signals in PlantMicrobe Communications, pp. 247-260. Edited by D. S. Verma. Boca Raton: CRC Press.

Takemoto, J. Y., Zhang, L., Taguchi, N., Tachikawa, T. \& Miyakawa, T. (1991). Mechanism of action of the phytotoxin syringomycin: a resistant mutant of Saccharomyces cerevisiae reveals an involvement of $\mathrm{Ca}^{2+}$ transport. J Gen Microbiol 137, 653-659.

Takemoto, J. Y., Yu, Y., Stock, S. D. \& Miyakawa, T. (1993). Yeast genes involved in growth inhibition by Pseudomonas syringae pv. syringae family lipodepsipeptides. FEMS Lett 114, 339-342.

Te Heesen, S., Janetzky, B., Lehle, L. \& Aebi, M. (1992). The yeast WBP1 is essential for oligosaccharyl transferase activity in vivo and in vitro. EMBO J 11, 2071-2075.

Townsley, F. M. \& Pelham, H. R. B. (1994). The KKXX signal mediates retrieval of membrane proteins from the golgi to the ER in yeast. Eur J Cell Biol 64, 211-216.

Zhang, L. \& Takemoto, J. Y. (1986). Mechanism of action of Pseudomonas syringae phytotoxin, syringomycin. Interaction with the plasma membrane of wild-type and respiratory-deficient strains of Saccharomyces cerevisiae. Biochim Biophys Acta 861, 201-204.

Zhang, L. \& Takemoto, J. Y. (1987). Effects of Pseudomonas syringae phytotoxin syringomycin on plasma membrane functions of Rhodotorula pilimanae. Phytopatbology 77, 297-303.

Zhang, L. \& Takemoto, J. Y. (1989). Syringomycin stimulation of potassium efflux by yeast cells. Biochim Biophys Acta 987, 171-175.

Received 4 July 1995; revised 25 October 1995; accepted 6 November 1995. 